\title{
Antiplatelet therapy with CABG: chaos in the Netherlands
}

\author{
F. W. A. Verheugt ${ }^{1}$
}

Published online: 13 July 2017

C) The Author(s) 2017. This article is an open access publication. Corrected publication August 2017.

One of the factors affecting the fate of arterial and venous bypass grafts in coronary artery bypass grafting (CABG) is optimal antithrombotic protection. Traditionally, antiplatelet therapy is the treatment of choice to protect grafts against occlusion [1]. Oral anticoagulants have shown to be effective as well [2], but not superior to antiplatelet agents [3]. Therefore, aspirin has become the standard of care in the prevention of graft occlusion [4]. Nowadays, a complicating factor is the use of dual antiplatelet therapy (DAPT) with aspirin and a P2Y12 blocker (clopidogrel, prasugrel or ticagrelor) in patients who have recovered from acute coronary syndromes (ACS) $[5,6]$. Not only do they have to undergo CABG for their index ACS, they may already be on DAPT when they become eligible for CABG. These considerations make the choice for antithrombotic protection in patients undergoing CABG complex.

In this issue of the Netherlands Heart Journal, Janssen et al. present the results of a survey amongst the cardiothoracic centres in the Netherlands on their strategies of perioperative antithrombotic therapy in CABG in the Netherlands [7]. The bottom line is that there is a large variation in the use of antithrombotic therapy around CABG, which was quite similar to the situation 27 years ago [8]. Furthermore, they show the results of a registry in their own centre which actually confirmed the disturbing findings in the rest of the country. The authors correctly conclude that this is due to

The original version of this article was revised because Table 1 was displayed incorrectly.

F. W. A. Verheugt

f.w.a.verheugt@olvg.nl

Department of Cardiology, Onze Lieve Vrouwe Gasthuis, Amsterdam, The Netherlands the lack of stringent guidelines on antiplatelet therapy in the field of coronary surgery.

With regards to preoperative aspirin, the majority of centres discontinue aspirin, which is not unanimously advised by the international guidelines (see below). In ACS patients P2Y12 blockers are discontinued between 4 and 7 days preoperatively in most centres, as mandated by the guidelines. Astonishingly, the majority of centres (including the reporting one) do not restart P2Y12 blockers after surgery in ACS patients. This is against the guidelines, because the benefit of restarting was already shown in CURE, the mother of all ACS trials on P2Y12 blockers [9].

There are few guidelines on the perioperative management of platelet inhibition in CABG. The most specific guideline from Europe [4] dates from 2008, and the American one is from 2014 [10]. The 2014 guideline issued by the European Association for Cardio-Thoracic Surgery [11] is not clear on this issue and focusses more on percutaneous revascularisation than CABG. A simplified recommendation for antiplatelet management in CABG is distilled from these guidelines and is given in Tab. 1 .

In conclusion, even in 2017 there is little consensus on antiplatelet strategies around CABG in the Netherlands. This is probably due to the rather vague international guidelines, which is a consequence of a relative paucity of evidence from randomised clinical trials. Because of the good results of cardiac surgery in the Netherlands, cardiothoracic centres should continue to follow their own clinical practice in the antiplatelet management in CABG.

Conflict of interest F. W. A. Verheugt has received honoraria for consulting and presentations from AstraZeneca, Eli Lilly and DaiichiSankyo. 
Table 1 Recommendation with level of evidence of timing and duration of antiplatelet therapy peri-CABG

\begin{tabular}{lllll}
\hline \multirow{2}{*}{ Timing } & Agent & $\begin{array}{l}\text { Stable CAD } \\
\text { without stent(s) }\end{array}$ & $\begin{array}{l}\text { CABG indication } \\
\text { Stable CAD } \\
\text { with recent stent(s) }\end{array}$ & $\begin{array}{l}\text { ACS } \\
\text { with or without stent(s) }\end{array}$ \\
\hline Preoperative & Aspirin & $\begin{array}{l}\text { Continue (IA) } \\
\text { n.a. }\end{array}$ & $\begin{array}{l}\text { Continue (IA) } \\
\text { Stop 5-7 days (IIA) }\end{array}$ & $\begin{array}{l}\text { Continue (IA) } \\
\text { Stop 5-7 days (IIA) }\end{array}$ \\
& P2Y12 & nop & Lifelong (IA) & Lifelong (IA) \\
\hline Postoperative & Aspirin & Lifelong (IA) & Day 1 restart (IIA) & Day 1 restart (IIB) \\
& P2Y12 & n.a. & & \\
\hline
\end{tabular}

n.a. not applicable

${ }^{a}$ Unless expected high perioperative bleeding risk

${ }^{b}$ Unless continued clinical instability

${ }^{\mathrm{c}}$ Duration depending on stent type and patient characteristics

${ }^{\mathrm{d}}$ Duration at least 1 year after index ACS
Open Access This article is distributed under the terms of the Creative Commons Attribution 4.0 International License (http:// creativecommons.org/licenses/by/4.0/), which permits unrestricted use, distribution, and reproduction in any medium, provided you give appropriate credit to the original author(s) and the source, provide a link to the Creative Commons license, and indicate if changes were made.

\section{References}

1. Chesebro JH, Fuster V, Elveback LR, et al. Effect of dipyridamole and aspirin on late vein-graft patency after coronary bypass operations. N Engl J Med. 1984;310:209-14.

2. Gohlke M, Gohlke-Bahrwolf C, Sturtzenhofecker P, et al. Improved graft patency with anticoagulant therapy after coronary bypass surgery: a prospective, randomized study. Circulation. 1981;64(Suppl II):II22-II7.

3. Van der Meer J, Hillige HL, Kootstra GJ, et al. Prevention of one-year vein-graft occlusion after aortocoronary bypass surgery: a comparison of low-dose aspirin, low-dose aspirin plus dipyridamole, and oral anticoagulants. Lancet. 1993;342:257-64.

4. Dunning J, Versteegh M, Fabbri A, et al. Guideline on antiplatelet and anticoagulant management in cardiac surgery. Eur J Cardiothorac Surg. 2008;34:73-92.

5. Steg PG, James SK, Atar D, et al. ESC Guidelines for the management of acute myocardial infarction in patients presenting with STsegment elevation. Eur Heart J. 2012;33:2569-619.
6. Roffi M, Patrono C, Collet JP, et al. ESC Guidelines for the management of acute coronary syndromes in patients presenting without persistent ST-segment elevation: Task Force for the management of acute coronary syndromes in patients presenting without persistent ST-segment elevation of the European Society of Cardiology (ESC). Eur Heart J. 2015;37:267-315.

7. Janssen PWA, Claassens DMF, Willemsen LM, Bergmeijer TO, Klein P, Ten Berg JM. Peroperative management of antiplatelet treatment in patients undergoing isolated coronary artery bypass grafting in Dutch cardiothoracic centers. Neth Heart J. 2017; . doi:10.1007/s12471-017-1006-z.

8. Galema TW, Verheugt FWA. Antithrombotica bij routine coronary bypass operaties in Nederland. Ned Tijdschr Geneeskd. 1990;134:1632-6.

9. Fox KAA, Mehta SR, Peters RJG, et al. Benefits and risks of the combination of clopidogrel and aspirin in patients undergoing surgical revascularization for non-ST elevation acute coronary syndrome: the CURE trial. Circulation. 2004;110:1202-8.

10. Kulik A, Ruel M, Jneid H, et al. Secondary prevention after coronary artery bypass graft surgery: a scientific statement from the American Heart Association. Circulation. 2015;131:927-64.

11. Kohl P, Windecker S, Alfonso F, et al. ESC/EACTS Guidelines on myocardial revascularization: the Task Force on Myocardial Revascularization of the European Society of Cardiology (ESC) and the European Association for Cardio-Thoracic Surgery (EACTS). Developed with the special contribution of the European Association of Percutaneous Cardiovascular Interventions (EAPCI). Eur J Cardiothorac Surg. 2014;46:517-92. 